\title{
Sensitivity analysis of ventricular activation and electrocardiogram in tailored models of heart-failure patients
}

\author{
Citation for published version (APA):
}

Sanchez, C., D'Ambrosio, G., Maffessanti, F., Caiani, E. G., Prinzen, F. W., Krause, R., Auricchio, A., \& Potse, M. (2018). Sensitivity analysis of ventricular activation and electrocardiogram in tailored models of heart-failure patients. Medical \& Biological Engineering \& Computing, 56(3), 491-504. https://doi.org/10.1007/s11517-017-1696-9

Document status and date:

Published: 01/03/2018

DOI:

10.1007/s11517-017-1696-9

\section{Document Version:}

Publisher's PDF, also known as Version of record

\section{Document license:}

Taverne

\section{Please check the document version of this publication:}

- A submitted manuscript is the version of the article upon submission and before peer-review. There can be important differences between the submitted version and the official published version of record. People interested in the research are advised to contact the author for the final version of the publication, or visit the DOI to the publisher's website.

- The final author version and the galley proof are versions of the publication after peer review.

- The final published version features the final layout of the paper including the volume, issue and page numbers.

Link to publication

\footnotetext{
General rights rights.

- You may freely distribute the URL identifying the publication in the public portal. please follow below link for the End User Agreement:

www.umlib.nl/taverne-license

Take down policy

If you believe that this document breaches copyright please contact us at:

repository@maastrichtuniversity.nl

providing details and we will investigate your claim.
}

Copyright and moral rights for the publications made accessible in the public portal are retained by the authors and/or other copyright owners and it is a condition of accessing publications that users recognise and abide by the legal requirements associated with these

- Users may download and print one copy of any publication from the public portal for the purpose of private study or research.

- You may not further distribute the material or use it for any profit-making activity or commercial gain

If the publication is distributed under the terms of Article $25 \mathrm{fa}$ of the Dutch Copyright Act, indicated by the "Taverne" license above, 


\title{
Sensitivity analysis of ventricular activation and electrocardiogram in tailored models of heart-failure patients
}

\author{
C. Sánchez ${ }^{1,2,8}$ (I) - G. D'Ambrosio ${ }^{3}$ - F. Maffessanti ${ }^{1}$ • E. G. Caiani ${ }^{4}$ - F. W. Prinzen ${ }^{5}$. \\ R. Krause ${ }^{1}$ - A. Auricchio ${ }^{1,3}$ - M. Potse ${ }^{1,6,7}$
}

Received: 6 October 2016 / Accepted: 20 July 2017 / Published online: 19 August 2017

(C) International Federation for Medical and Biological Engineering 2017

\begin{abstract}
Cardiac resynchronization therapy is not effective in a variable proportion of heart failure patients. An accurate knowledge of each patient's electroanatomical features could be helpful to determine the most appropriate treatment. The goal of this study was to analyze and quantify the sensitivity of left ventricular (LV) activation and the electrocardiogram (ECG) to changes in 39 parameters used to tune realistic anatomical-electrophysiological models of
\end{abstract}

Electronic supplementary material The online version of this article (https://doi.org/10.1007/s11517-017-1696-9) contains supplementary material, which is available to authorized users.

C. Sánchez

cstapia@unizar.es

1 Center for Computational Medicine in Cardiology (CCMC), Institute of Computational Science, Università della Svizzera italiana, Lugano, Switzerland

2 General Military Academy of Zaragoza (AGM), Defense University Centre (CUD), Zaragoza, Spain

3 Division of Cardiology, Cardiocentro Ticino, Lugano, Switzerland

4 Electronics, Information, and Bioengineering Department, Politecnico di Milano, Milan, Italy

5 Cardiovascular Research Institute Maastricht (CARIM), Maastricht University, Maastricht, The Netherlands

6 IHU LIRYC, Université de Bordeaux, Pessac, France

7 Inria Bordeaux Sud-Ouest, Talence, France

8 Present address: Biosignal Interpretation and Computational Simulation Group (BSICoS), Engineering Research Institute of Aragon (I3A), University of Zaragoza, Zaragoza, Spain the heart. Electrical activity in the ventricles was simulated using a reaction-diffusion equation. To simulate cellular electrophysiology, the Ten Tusscher-Panfilov 2006 model was used. Intracardiac electrograms and 12-lead ECGs were computed by solving the bidomain equation. Parameters showing the highest sensitivity values were similar in the six patients studied. QRS complex and LV activation times were modulated by the sodium current, the cell surface-tovolume ratio in the $\mathrm{LV}$, and tissue conductivities. The Twave was modulated by the calcium and rectifier-potassium currents, and the cell surface-to-volume ratio in both ventricles. We conclude that homogeneous changes in ionic currents entail similar effects in all ECG leads, whereas the effects of changes in tissue properties show larger inter-lead variability. The effects of parameter variations are highly consistent between patients and most of the model tuning could be performed with only $\sim 10$ parameters.

Keywords Computer simulation · ECG morphology · Heart failure - Left bundle branch block - Patient-specific model $\cdot$ Sensitivity analysis

\section{Introduction}

Heart failure (HF) is one of the most commonly diagnosed cardiac diseases with an overall incidence approaching one percent of the population over 65 years of age [39]. A significant percentage of HF patients presents a prolonged QRS duration on the 12-lead electrocardiogram (ECG), and many of them are diagnosed with left bundle branch block (LBBB), indicating impairment of the cardiac conduction system specifically in the left ventricle (LV) [14]. Cardiac resynchronization therapy (CRT) has been shown to reduce 
mortality in most patients with clear LBBB, but its efficacy is reduced in patients with other concomitant electrical abnormalities, such as right bundle branch block, or diffuse ventricular conduction disturbances [57]. Better prediction of CRT efficacy in each particular HF patient through accurate description of their electrophysiology would help to avoid unnecessary surgical interventions. Computational models are a powerful tool to achieve this without ethical limitations.

Recent studies have shown the usefulness of patientspecific models to study complex electrophysiological phenomena in healthy and diseased subjects [28, 35]. However, it is challenging to create multiscale models able to mimic in a realistic way the entire ventricular electrical behavior from the subcellular level to the whole heart and body surface levels. Without prior knowledge, the tuning of patient-specific models is hampered by the high number of parameters involved, which may differ between patients, creating an ill-posed problem. Therefore, doing a sensitivity analysis is meant to quantify to what extent each single parameter affects the output and, finally, to identify those needing accurate tuning. Previous sensitivity analysis studies in silico have shown that extracellular conduction properties in the different anatomical structures (blood, lungs, fat, skeletal muscle...) of a human torso affect in different ways the electrical potentials measured at the body surface $[5,19]$.

In this study, we created realistic models of both the anatomy and the electrical activation in six HF patients selected for CRT. The main purpose of the analysis performed in this work was to investigate the relative importance of myocardial properties in determining both the activation sequence on the LV endocardial surface and the ECG morphology in HF patients. For this analysis, individual variations of 39 parameters, including intracellular and extracellular tissue conductivity, and cellular membrane ionic properties, were evaluated. This set of 39 parameters is too large to tune a patient-specific model efficiently. Therefore, a second goal of this study was to delimit the number of parameters that are required for model tuning.

\section{Methods}

\subsection{Patients}

Six patients, with ages ranging from 53 to 79 years, diagnosed with $\mathrm{HF}$ and suitable for CRT implantation according to the criteria from the 2011/2013 ESC clinical practice guidelines [6] were included in this study (Table 1). Four of the six patients showed clear LBBB electrocardiographic features according to three widely used sets of criteria: the criteria used by the European Society of Cardiology (ESC) [3], the criteria used by the American Heart Association (AHA) [49], and the criteria proposed by Strauss et al. [48]. The other two patients had non-specific ventricular conduction disturbances. These six patients underwent standard 12-lead ECG, cardiac magnetic resonance (CMR) imaging, electro-mechanical anatomical mapping (NOGA $\mathrm{XP}$, Biosense Webster), and a coronary angiography procedure. In four of the six patients, the NOGA catheter was introduced in the left-ventricular (LV) cavity and had contact with the endocardium only, whereas in patients 5 and 6 the electrical activation on both right ventricular (RV) and LV endocardium as well as the ventricular epicardial layer underneath the coronary sinus was measured. Details of the data collection procedure were described in a previous study [35]. Data for the six patients were collected between 2012 and 2015 at Cardiocentro Ticino (Lugano, Switzerland). The patients provided written consent to each procedure, and the institutional review board approved the use of the data for research purposes.

Table 1 Selected patient demographics and characteristics

\begin{tabular}{llllllllll}
\hline Patient & Age & Gender & Height $(\mathrm{m})$ & Weight $(\mathrm{kg})$ & LVEF $(\%)$ & NYHA & Etiology & QRSd (ms) & Morph. \\
\hline 1 & 72 & Female & 1.57 & 75 & 39 & III-IV & CAD & 139 & LBBB \\
2 & 69 & Male & 1.82 & 75 & 35 & II-III & IDCM & 179 & LBBB \\
3 & 79 & Male & 1.87 & 94 & 28 & II-III & CAD & 138 & IVCD \\
4 & 57 & Male & 1.60 & 67 & 30 & II-III & CAD & 126 & IVCD \\
5 & 73 & Male & 1.70 & 80 & 24 & III-IV & IDCM & 154 & LBBB \\
6 & 53 & Male & 1.78 & 110 & 34 & II-III & IDCM & 145 & LBBB \\
\hline
\end{tabular}

$L V E F$ left ventricular ejection fraction, NYHA New York Heart Association Functional Classification, $Q R S d$ QRS duration, $C A D$ coronary artery disease, IDCM idiopathic dilated cardiomyopathy, $L B B B$ left-bundle-branch block, IVCD intraventricular conduction delay 


\subsection{Model construction}

Anatomical segmentation Segmentation of cardiovascular structures, lungs, and torso of each patient was performed based on CMR data obtained with a 3T Siemens Magnetom Skyra Scanner equipped with a dedicated cardiac 36-channel coil and a standard body coil for thorax examinations. CMR images were obtained in axial, coronal, sagittal, cardiac short axis, and cardiac long axis planes, with a slice thickness between 1 and $8 \mathrm{~mm}$ [35]. Late gadolinium-enhancement images for scar detection were obtained $10 \mathrm{~min}$ after intravenous infusion of gadolinium (Gadobutrol, $0.2 \mathrm{mmol} / \mathrm{kg}$ body weight) using a T-weighted gradient-echo pulse sequence with a phase-sensitive inversion recovery reconstruction. Semi-automatic segmentation of ventricular epicardium and endocardium was performed as described in a previous study [12]. Atrial cavities, aorta, inferior and superior vena cava, and pulmonary trunk were manually segmented using custom-made software for tracing contours. Lungs, torso, and ECG electrode locations were manually traced on ultra-fast volume-interpolated breath-hold examination (VIBE) images following the injection of the contrast agent.

Mesh construction The segmentation contours were used to generate a three-dimensional (3D) mesh of the tissue boundaries. Mesh construction, i.e., creation of closed surfaces representing the different structures, was performed using the Blender software (The Blender Foundation, Amsterdam, The Netherlands). All cardiovascular structures were joined to define a 3D model of the heart, which together with the lungs and torso meshes constituted the complete anatomical model of the patient. In order to extract the 12-lead ECG from the simulations, nine virtual electrodes were placed on the torso surface at the same locations as in the real patients: three for the limb leads, and six for the precordial leads. Both in reality and in the model, the arm electrodes were placed on the shoulders and the left-leg electrode was placed near the hip.

Definition of tissue properties From the surface meshes defining the anatomy, volumetric meshes for the computations were created. Since the computational code worked with semi-structured finite-difference meshes, this conversion consisted of simply overlaying the surfaces on a regular 3D grid and assigning tissue types to the grid elements according to the surfaces in which they were contained. We used a mesh with 0.2-mm spacing for the heart and 1$\mathrm{mm}$ spacing for the torso. Passive tissue properties were associated with grid elements, while model variables and active properties such as densities of ionic currents were associated with the nodes of the grid [33]. The node types, which determine the parameters of the ionic model, were determined from the element types using a set of rules that ensure model consistency [33]. The passive properties were the scalar conductivities $(\sigma)$ in longitudinal, transversal and cross-sheet directions, and cell surface-to-volume ratio $(\beta)$, i.e., the amount of cellular membrane per unit volume. For ventricular myocardium, fiber rotation from endocardial to epicardial layers was included by using a rule-based method [33]. Four layers were simulated in the myocardium: epicardium (the most external layer), midmyocardium (middle layer), endocardium (inner layer), and a thin fast endocardial layer $(0.6 \mathrm{~mm})$ to mimic the rapid propagation occurring due to the Purkinje system in the endocardium. The first three layers (epicardium, midmyocardium, and endocardium) were differentiated by their cellular electrophysiology [55]. A full layer was used to represent the network of Purkinje fibers because the actual topology cannot be recorded in vivo [27]. This fast endocardial layer was initially assumed to have the same properties in both ventricles, although previous studies proposed to differentiate them for the stimulation profile $[18,41]$.

\subsection{Electrophysiological simulation}

Cardiac electrophysiology was simulated with a monodomain reaction-diffusion model [33]. Electrophysiological activity of ventricular myocytes was simulated using the Ten Tusscher and Panfilov 2006 membrane model, which includes transmembrane ionic currents, regulation of sodium, potassium, and calcium intracellular ion concentrations, and intracellular calcium handling in the sarcoplasmic reticulum [55]. The ECG was simulated by solving the extracellular potential $\phi_{\mathrm{e}}$ from the equation

$\nabla \cdot\left(\left[G_{\mathrm{i}}+G_{\mathrm{e}}\right] \nabla \phi_{\mathrm{e}}\right)=-\nabla \cdot\left(G_{\mathrm{i}} \nabla V_{\mathrm{m}}\right)$

where $G_{\mathrm{i}}$ and $G_{\mathrm{e}}$ are the intracellular and extracellular conductivity tensor fields, respectively, and $V_{\mathrm{m}}$ is the transmembrane potential field [34]. The reaction-diffusion simulation was run on a mesh with $0.2 \mathrm{~mm}$ resolution. The right-hand side of Eq. 1 was evaluated on this fine mesh and then projected on the coarser $(1 \mathrm{~mm})$ torso mesh, which included a downsampled model of the heart. $\phi_{\mathrm{e}}$ was solved on the coarse mesh. The 12-lead ECG was then computed by extracting the extracellular potential at the electrode locations.

All simulations were performed using propag-5, software specifically created for cardiac simulation and parallelizable to utilize supercomputing facilities of the Swiss National Supercomputing Centre (CSCS) [22, 33]. Most simulations ran on 1536 cores of a Cray XC40 system. Computation 
times for each single simulation were in the range of 40 to $60 \mathrm{~min}$ for $600 \mathrm{~ms}$ of simulations of $V_{\mathrm{m}}$ and $\phi_{e}$.

\subsection{Endocardial activation map and ECG matching}

Once the model was complete, parameter adjustments were iteratively performed in order to match as closely as possible the electrical activation pattern measured with the NOGA catheter on the endocardial surface, as well as the morphological features of the clinically obtained ECG. In this study, electrical activity was only generated in the ventricular myocardium. Therefore, the P-wave was not simulated and the ECG analysis was focused on the QRS complex and the T-wave. Figure 1 shows the modeled RV and LV endocardial surfaces of patient 5 together with the measured activation times (color-coded) at 396 NOGA recording sites for this patient. Activation time at a recording site was computed as the time interval between the QRS onset (vertical red line on the right panel of Fig. 1) and the steepest negative deflection of the electrogram (blue dot on the right panel of Fig. 1).

The iterative strategy of parameter adjustments differed between patients, but in general consisted of (1) finding the appropriate number and locations of early activation sites to match the initiation of the LV activation, (2) tuning surface-to-volume ratios, conductivities, and the sodium current conductance to adjust the conduction velocity in the myocardium until good matching in the LV activation pattern was obtained, (3) refining adjustments performed in step 2 to improve matching of the QRS complex, (4) adjusting properties of the L-type calcium current and potassium currents to match the T-wave. Note that changes in surfaceto-volume ratios, conductivities, and the sodium current conductance affect conduction velocity, but the way they do it may be different, so steps (2) and (3) are typically performed simultaneously: changes in surface-to-volume ratios modify propagation features homogeneously in a specific part of the ventricles (LV, RV, septum...); changes in conductivities allow us modify propagation features of cardiac tissue anisotropically in specific directions (longitudinal, transversal, or cross-sheet); and changes in the sodium current conductance modify excitability of cardiac cells based on their type in both the LV and the RV (endocardial cell, $\mathrm{M}$ cell, or epicardial cell). Tuning was stopped when we could not find a way to improve it further. Parameters were changed in physiologically plausible ways, e.g. changes in $\beta$ and $\sigma$ in some patients corresponded to hypertrophied hearts. A complete list of tuned parameters and tailored models for the six patients is shown in Supplemental Material.

Figure 2 shows the anatomical models of the six patients together with leads I, aVL, V5 and V6 of the measured ECG (red) and simulated ECG (black). These four leads were chosen due to their importance for LBBB diagnosis. On the right panels of Fig. 2, correlation between simulated and measured activation times is shown, including the fitted line and the correlation coefficient.

\subsection{Univariate sensitivity analysis}

A quantitative analysis to evaluate the relative importance for the cardiac electrical activity of individual parameters in the model was performed. Two groups of parameters
Fig. 1 Modeled endocardial surfaces of RV and LV for patient 5 and measured activation times at NOGA recording sites in a color scale (left panel). Example of an electrogram recorded at the LV endocardium at the position of the crosshair in the left panel (right panel), together with the time of QRS onset (vertical red line) and the activation time (blue dot)

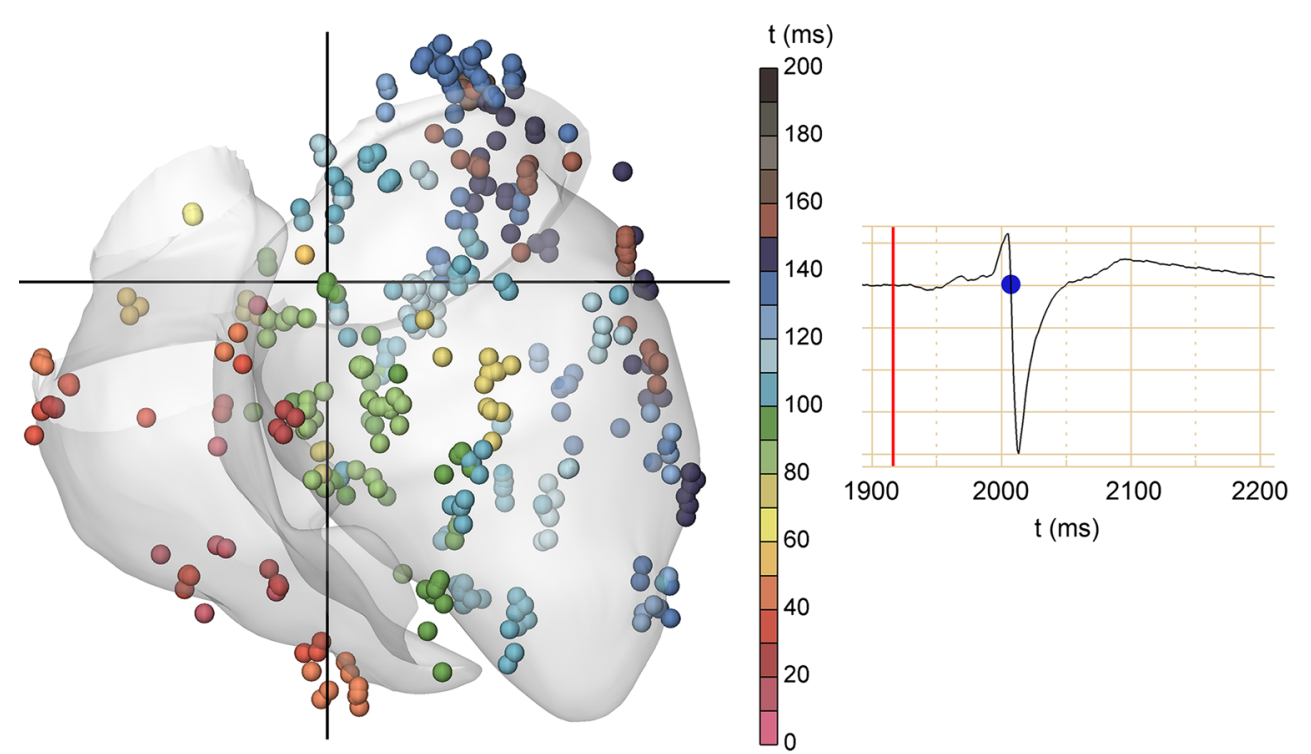



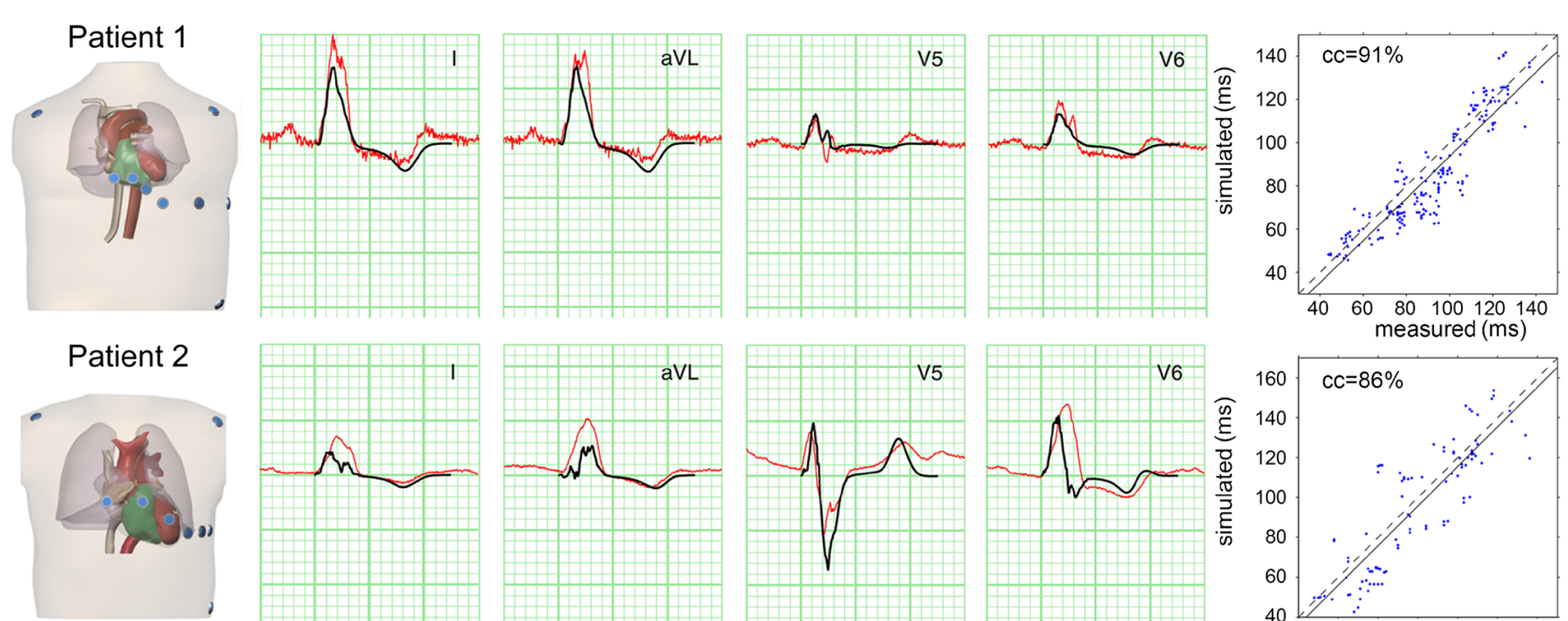

Patient 3
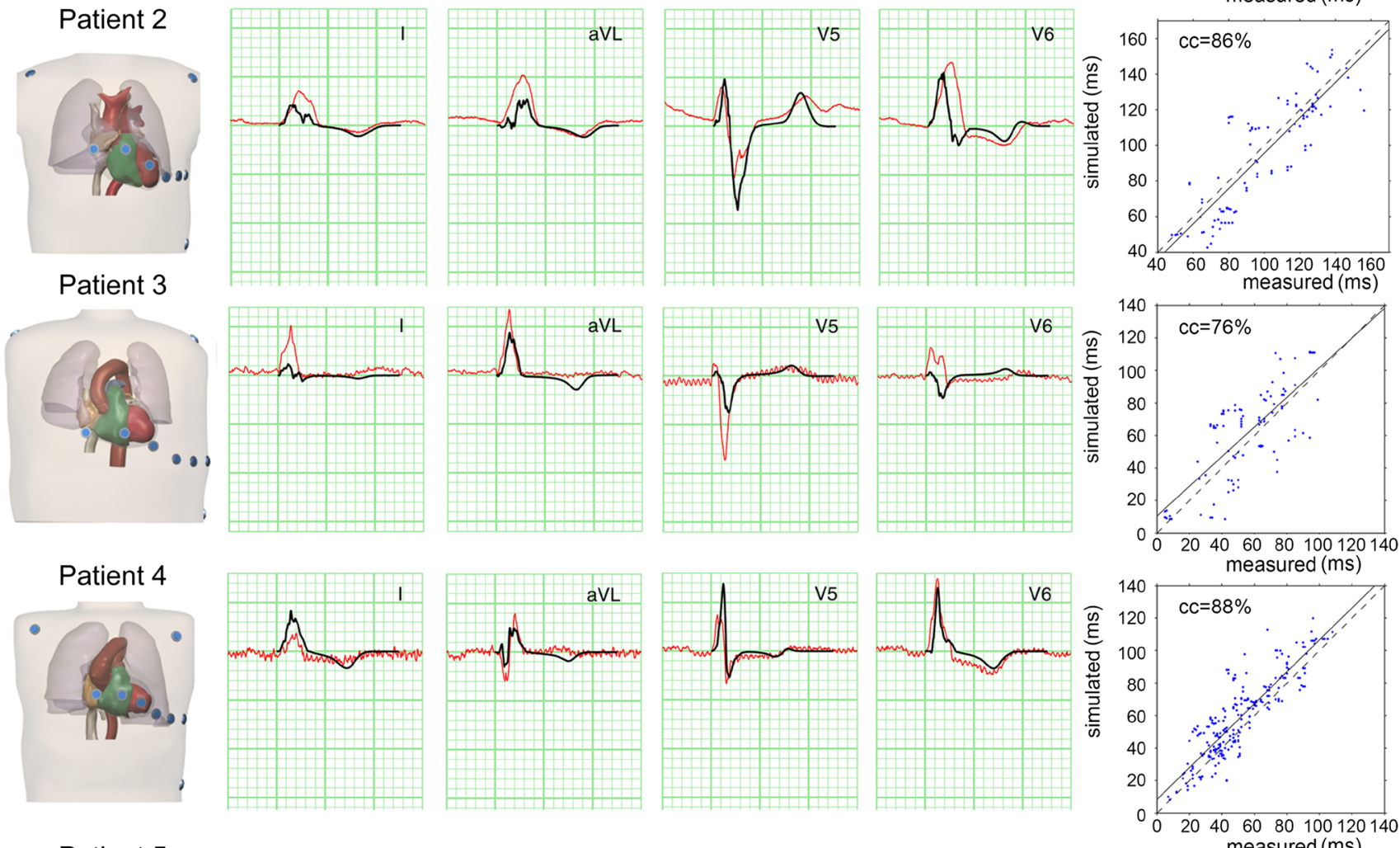

Patient 5
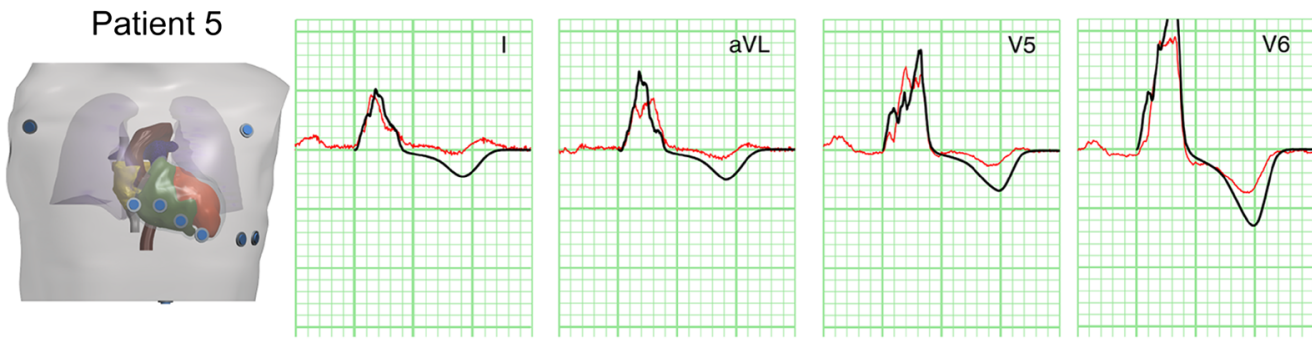

Patient 6
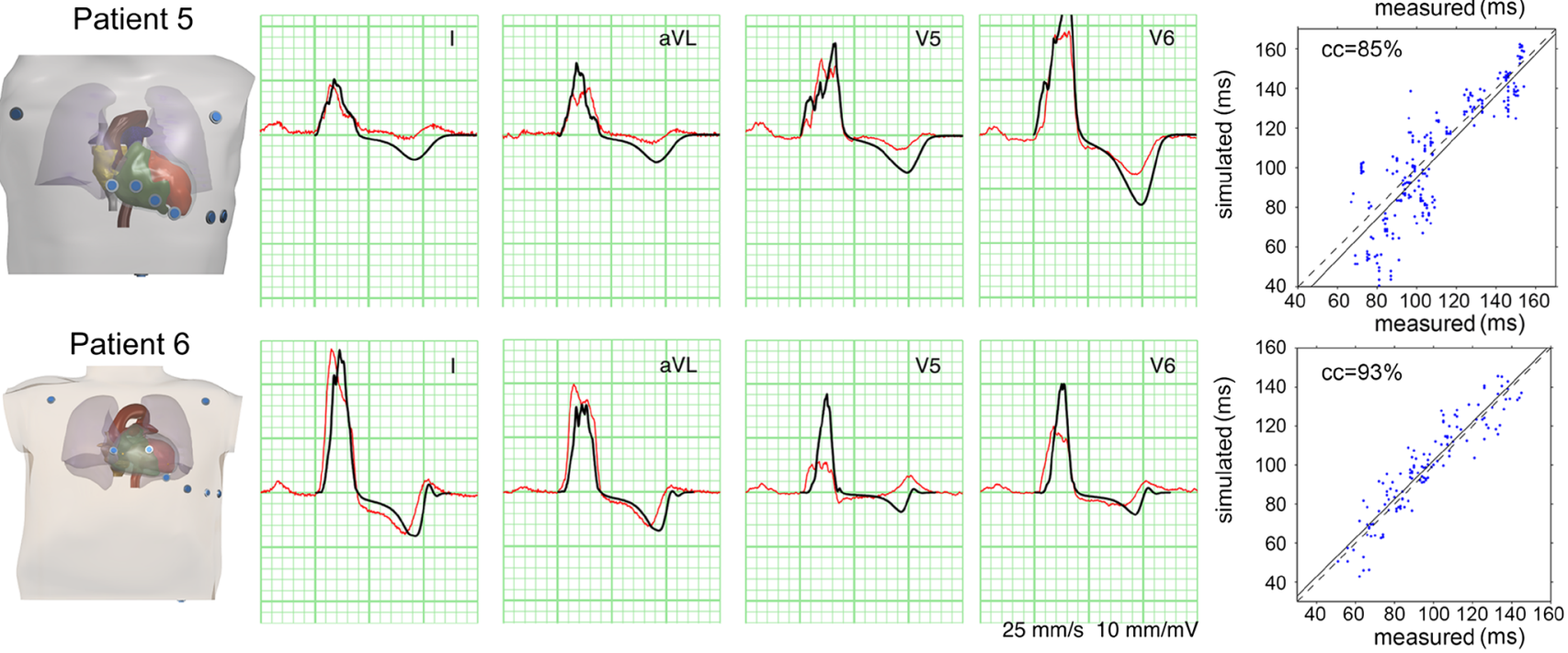

Fig. 2 Anatomical models of the six patients (left), and corresponding measured (red), and simulated ECG (black) in leads I, aVL, V5, and V6. Correlation between simulated and measured activation times on the LV endocardium (right) 
were distinguished: those characterizing cellular ionic properties, and those characterizing passive electrical properties of the tissue. In the first group, maximum conductances of all transmembrane ionic currents were included: fast sodium current $\left(I_{\mathrm{Na}}\right)$, L-type calcium current $\left(I_{\mathrm{CaL}}\right)$, inward rectifier potassium current $\left(I_{\mathrm{K} 1}\right)$, transient outward current $\left(I_{\mathrm{to}}\right)$, rapid delayed rectifier potassium current $\left(I_{\mathrm{Kr}}\right)$, slow delayed rectifier potassium current $\left(I_{\mathrm{Ks}}\right)$, sodium/potassium pump current $\left(I_{\mathrm{NaK}}\right)$, and sodium/calcium exchanger current $\left(I_{\mathrm{NaCa}}\right)$; and also two parameters to modify inactivation kinetics of $I_{\mathrm{CaL}}\left(\tau_{\mathrm{f}}\right)$ and activation kinetics of $I_{\mathrm{Ks}}\left(\tau_{\mathrm{xs}}\right)$, known to be relevant in the adaptation of cell repolarization to heart rate [36]. These parameters were chosen in agreement with their importance in determining ventricular cell properties as shown in a previous study [40]. The second group of parameters consisted of cell surface-to-volume ratio $(\beta)$, intracellular conductivities $\left(\sigma_{i}\right)$, and extracellular conductivities $\left(\sigma_{\mathrm{e}}\right)$ in the three directions of propagation: longitudinal $\left(\sigma_{\mathrm{il}}\right.$ and $\left.\sigma_{\mathrm{el}}\right)$, transversal $\left(\sigma_{\mathrm{it}}\right.$ and $\left.\sigma_{\mathrm{et}}\right)$, and crosssheet $\left(\sigma_{\mathrm{ic}}\right.$ and $\left.\sigma_{\mathrm{ec}}\right)$. They were analyzed separately for each tissue type: LV, RV, fast endocardial layer (fendo), blood, skeletal muscle, and lungs. In the rest of this manuscript, the tissue type will be shown as an additional subscript of $\beta$ and $\sigma$. In total, changes in 39 parameters were studied.

To quantify the effects of each parameter on particular ECG markers and ventricular activation, $\pm 30 \%$ changes with respect to the adjusted values of the model for each patient were simulated, in agreement with the magnitude of changes (25-30\%) reported in previous studies [11, 19, 40, 42, 43].

Ten ECG markers were computed for each of the 12 ECG leads: QRS peak time, absolute value of QRS amplitude with respect to the baseline, QRS area, QRS skewness, QRS kurtosis, QRS peak-T peak interval, absolute value of T-wave amplitude with respect to the base line, T peak time, $\mathrm{T}$-wave skewness, and T-wave kurtosis (examples of some of these markers are shown in Fig. 3). Furthermore, catheter positions were projected on the simulated endocardial surface so that simulated activation times and measured activation times could be compared. Linear regression between the simulated and measured activation times was performed, and the slope of the fitted line was also included in the sensitivity analysis.

The sensitivity of a marker, $m$, to changes in a particular parameter, $p$, was quantified by computing:

$S_{m, p}(\%)=\frac{m_{p+30 \%}-m_{p-30 \%}}{0.6 m_{p \pm 0 \%}} 100$

where $m_{p+30 \%}, m_{p-30 \%}$, and $m_{p \pm 0 \%}$ are the values of the marker $m$ when the parameter $p$ is varied by $+30 \%$, $-30 \%$ and $\pm 0 \%$ (unvaried), respectively, with respect to their default value in the model. A factor of 0.6 is included to account for the $60 \%$ range of variation. The computed value,

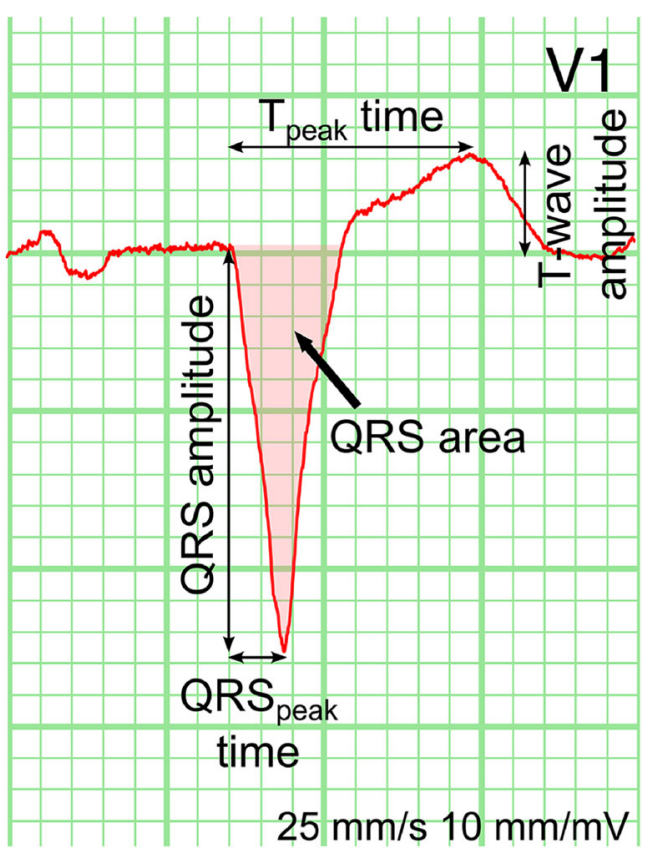

Fig. 3 Example of lead V1 of a clinically measured ECG with five of the markers included in the sensitivity analysis: QRS peak time, QRS amplitude, QRS area, T peak time and T-wave amplitude

$S_{m, p}$, represents the percentage of variation of the marker $m$ if the parameter $p$ were varied by $100 \%$, considering the effect of changes as linear.

A model parameter was considered to be relevant in the modulation of a marker if the sensitivity value was higher than $50 \%$ of the maximum sensitivity among all parameters for that particular marker. In the ECG markers, this consideration was taken in each of the 12 leads separately.

\section{Results}

Figure 4 shows examples of simulations conducted for the parameter sensitivity analysis. In particular, effects of changes in $I_{\mathrm{Na}}$ on the I, aVR, V5 and V6 ECG leads (a), LV endocardial activation map (b), displayed as a 2D polar diagram showing measured and simulated activation times in a color scale, and linear fit between simulated and measured activation times (c) are displayed. In this example, average computed values for sensitivity to $I_{\mathrm{Na}}$ changes were highly relevant for $\mathrm{QRS}$ peak time $\left(S_{\mathrm{QRSpeak}, \mathrm{I}_{\mathrm{Na}}}=-30.1 \%\right)$, QRS area $\left(S_{\mathrm{QRSarea}, \mathrm{I}_{\mathrm{Na}}}=-35.8 \%\right)$, and QRS morphology $\left(S_{\mathrm{QRSskew}, \mathrm{I}_{\mathrm{Na}}}=-193.6 \%, S_{\mathrm{QRSkurt}, \mathrm{I}_{\mathrm{Na}}}=11.1 \%\right)$. Regarding the T-wave, the sensitivities of the T-wave amplitude $\left(S_{\mathrm{Tamp}, \mathrm{I}_{\mathrm{Na}}}=-34 \%\right)$ and the T-wave morphology were also relevant $\left(S_{\text {Tskew }, \mathrm{I}_{\mathrm{Na}}}=52.1 \%, S_{\mathrm{Tkurt}, \mathrm{I}_{\mathrm{Na}}}=30.5 \%\right)$. $I_{\mathrm{Na}}$ changes entailed minimal effects on QRS amplitude $\left(S_{\mathrm{QRSamp}, \mathrm{I}_{\mathrm{Na}}}=3 \%\right)$, T-wave peak time $\left(S_{\mathrm{Tpeak}, \mathrm{I}_{\mathrm{Na}}}=\right.$ $-7,8 \%)$, and QRS-T interval $\left(S_{\mathrm{QRS}-\mathrm{T}, \mathrm{I}_{\mathrm{Na}}}=-1.1 \%\right)$ in this 
Fig. 4 Simulation results. a ECG for patient 2. Leads I, aVR, $\mathrm{V} 5$, and $\mathrm{V} 6$ with $I_{\mathrm{Na}}$ reduction by $30 \%$ (blue), no changes (black), and $I_{\mathrm{Na}}$ increase by $30 \%$ (red). b Polar diagram of the LV endocardium showing measured activation times (circles with time in milliseconds) and simulated activation times (colored dots). Apex is marked with a cross, ' + ', at the center of the diagram. c Simulated versus measured activation times on the LV endocardium. Correlation coefficients are shown a
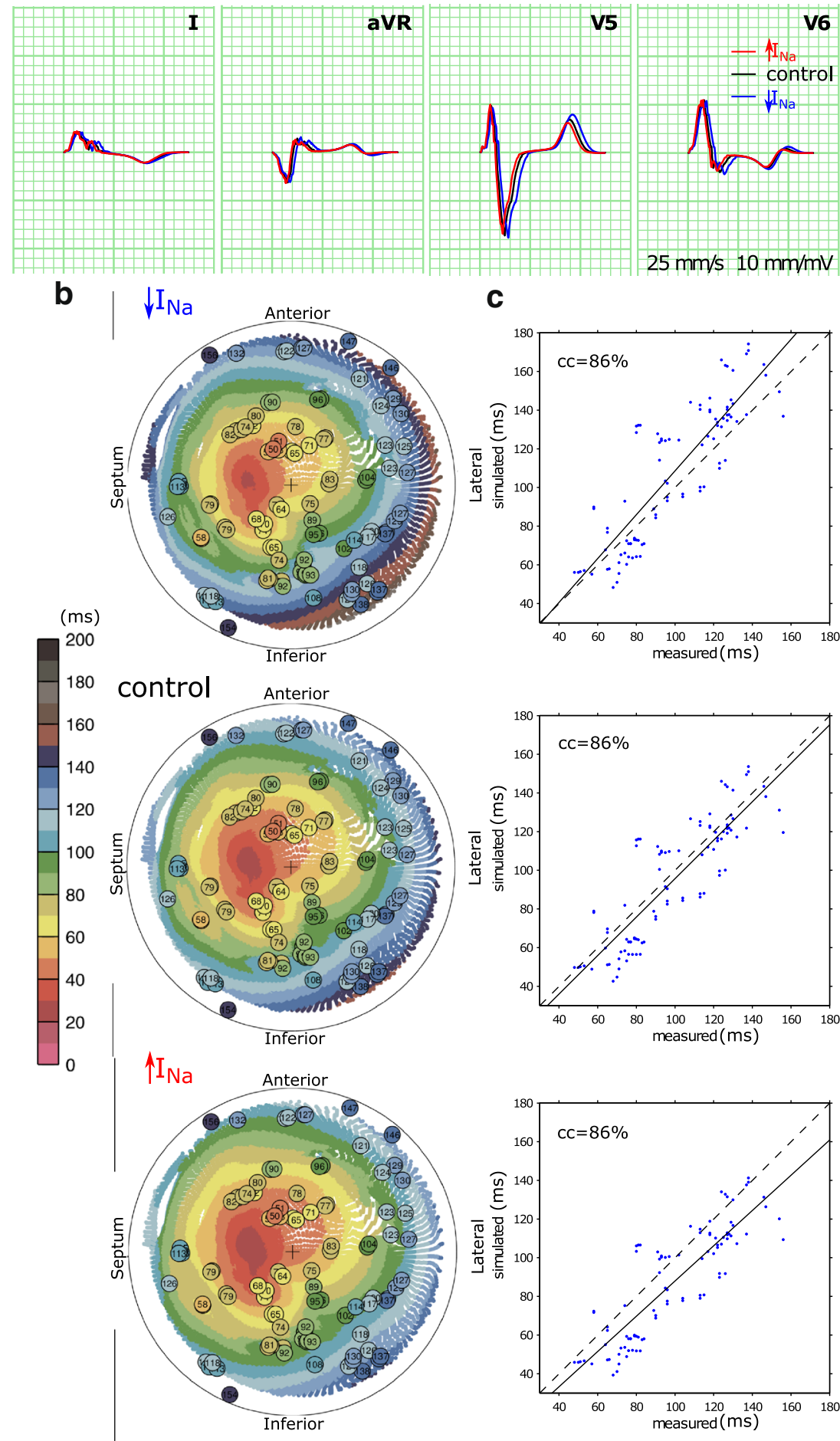
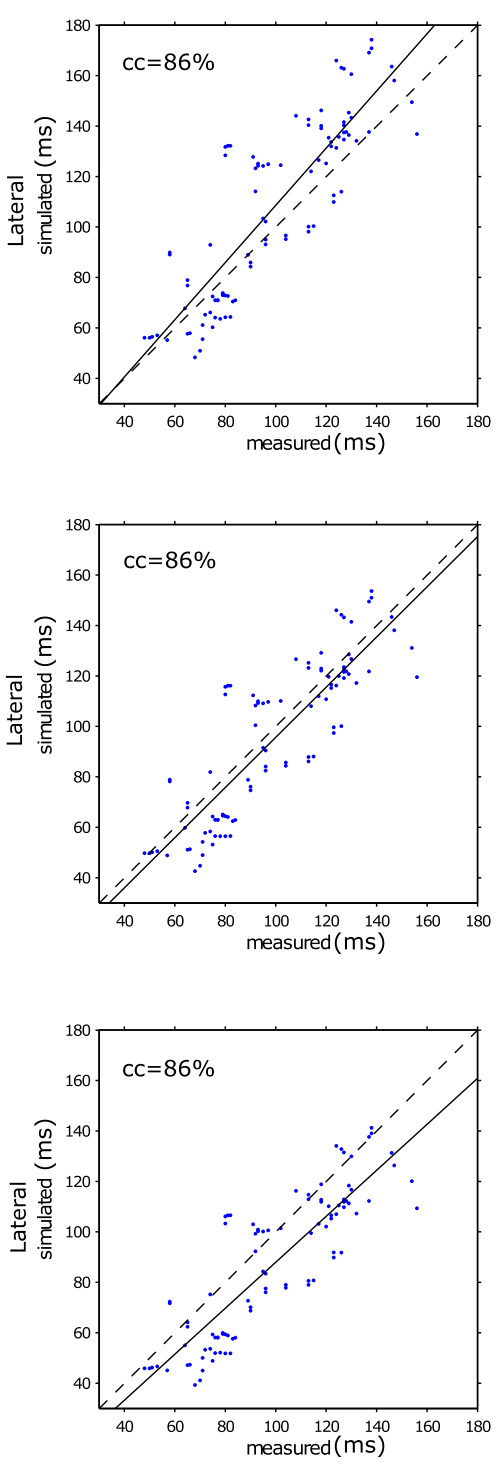

patient. Furthermore, effects of $I_{\mathrm{Na}}$ changes on the linear fitted slope were also notable $\left(S_{\mathrm{LV} \text { slope, } \mathrm{I}_{\mathrm{Na}}}=-37 \%\right)$. Negative sensitivity values reflected that an increase in $I_{\mathrm{Na}}$ led to a decrease in the analyzed marker, and vice versa.

In general, the parameters showing the highest sensitivity values were similar in the six patients. Figures 5, 6, and 7 show the parameters whose variations exerted the strongest alterations on LV activation and ECG markers, respectively, in the six patients. Figure 5 shows the sensitivity values (horizontal axis) for each relevant parameter (vertical axis) and patient (color coded). In Figs. 6 and 7, each horizontal line represents the average sensitivity value \pm standard deviation for the $12 \mathrm{ECG}$ leads for a particular parameter (vertical axis) and patient (color coded). 


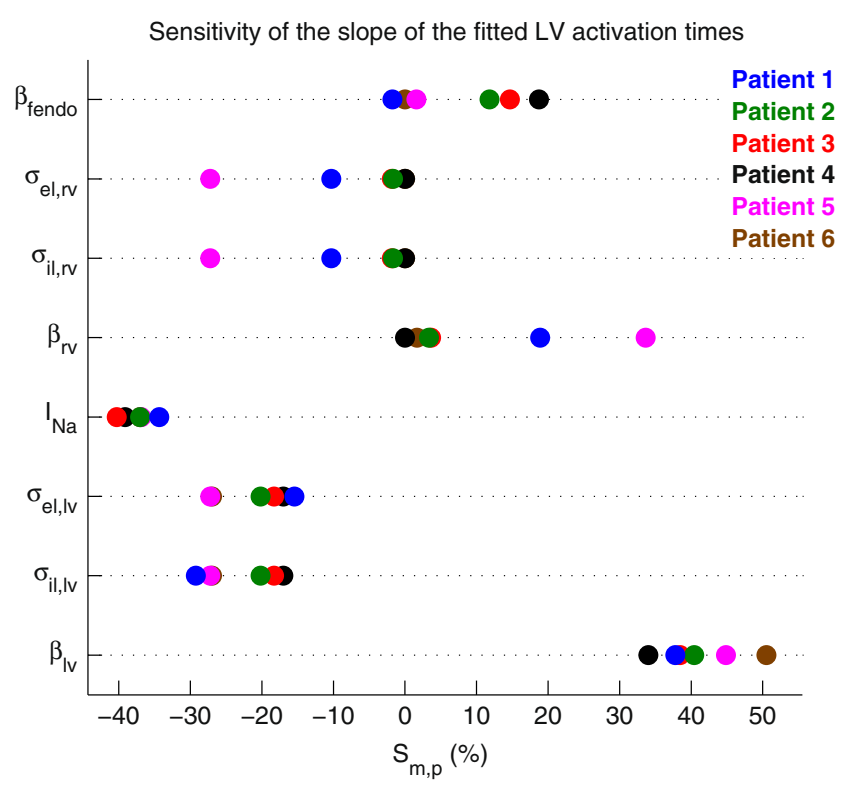

Fig. 5 Significant parameters following sensitivity analysis results for the slope of the fitted line between simulated and measured activation times for the six patients (different colors for each patient)

LV activation The slope of the fitted line between simulated and measured activation times was sensitive to several parameters, all related to conduction velocity in the myocardium in both ventricles, as shown in Fig. 5. Effects were consistent between the six patients, but it was observed that changes in the tissue properties of the RV only entailed significant variations in the slope in patient 5 and, to a lesser extent, patient 1 . This was probably due to anatomical particularities in the septum properties and the early activation sites of these patients (see Supplemental Material).

QRS-complex morphology As shown in Fig. 6, QRS peak time was mainly determined by those parameters affecting conduction velocity in the myocardium such as $I_{\mathrm{Na}}, \beta_{\mathrm{LV}}$, and $\beta_{\mathrm{RV}}$. Parameters affecting conductivity in the fast endocardial layer, like $\beta_{\text {fendo }}, \sigma_{\text {il,fendo }}$, or $\sigma_{\text {el,fendo }}$, also affect QRS peak time, but they are not represented in Fig. 6 because they are not so notable. Variations in QRS amplitude were observed when applying changes in conduction properties in both ventricles, but also changes in some conductivities of the torso: $\sigma_{\mathrm{e} \text {,musc }}$ (simultaneous changes in the three directions), and $\sigma_{\mathrm{et} \text {,musc }}$ (changes only in the transversal direction). Similarly, QRS area was mainly modulated by changes in conduction in the LV: $\beta_{\mathrm{LV}}$ (with a large variability between leads), $\sigma_{\mathrm{il}, \mathrm{LV}}$ and $\beta_{\text {fendo }}$; but also by $I_{\mathrm{Na}}$ and $\sigma_{\mathrm{e} \text {,blood. Morphology-related parameters like skewness }}$ and kurtosis were also modulated by the surface-to-volume ratios in the $\mathrm{LV}$, the $\mathrm{RV}$ and the fast endocardial layer, and by $I_{\mathrm{Na}}$ and $\sigma_{\mathrm{il}, \mathrm{LV}}$. Changes in $\sigma_{\mathrm{e}, \text { lung }}$ have some effects on QRS kurtosis in some of the patients, but their effects are not

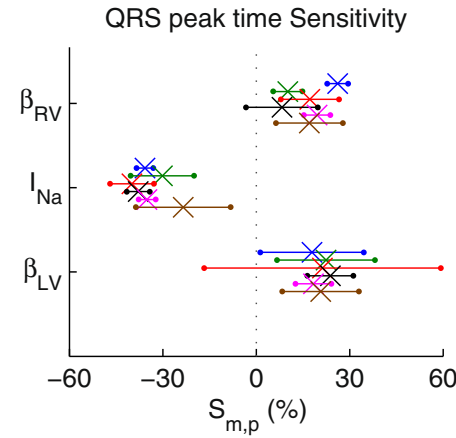

QRS-T interval Sensitivity
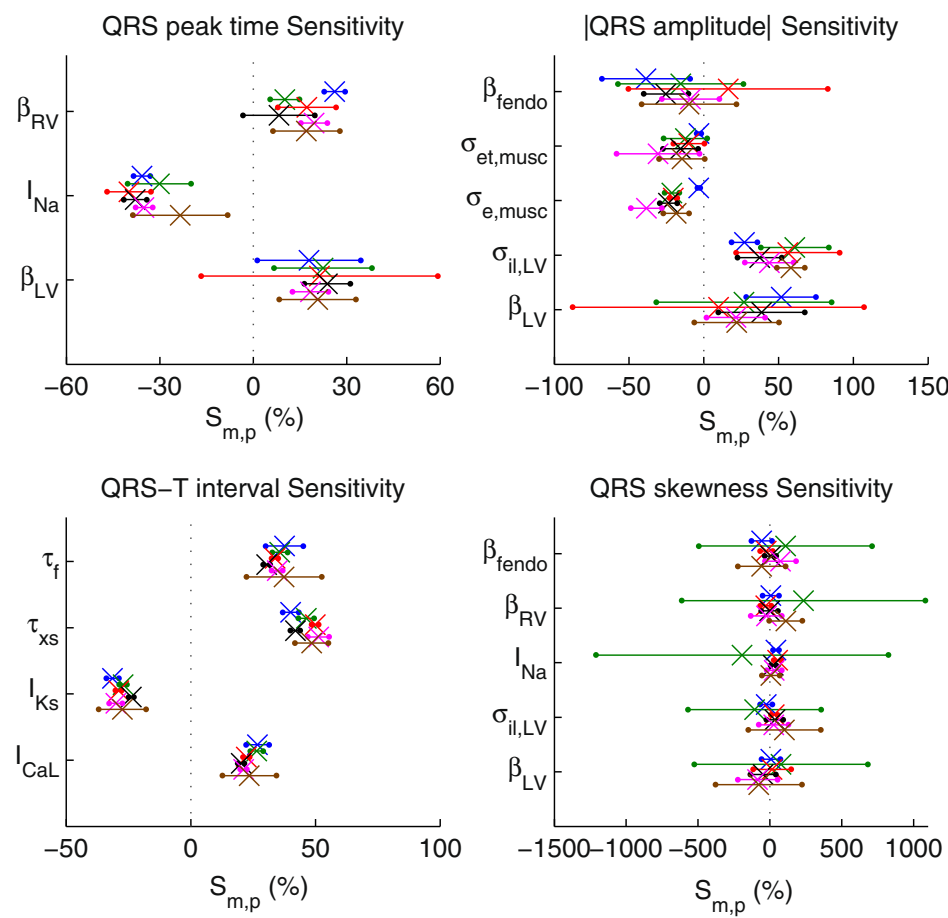

QRS skewness Sensitivity

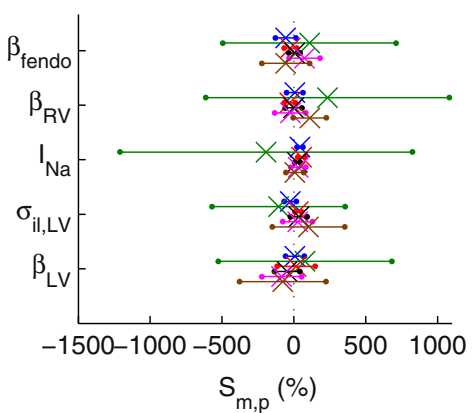

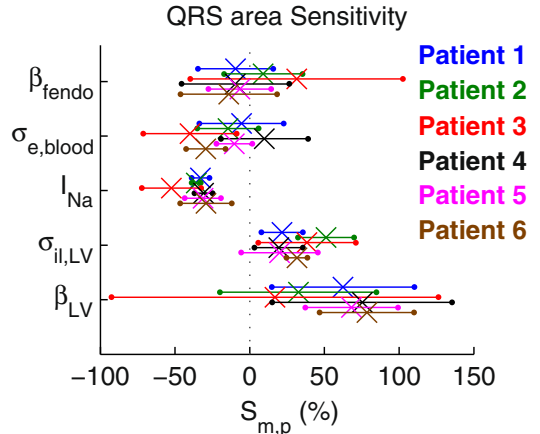

QRS kurtosis Sensitivity

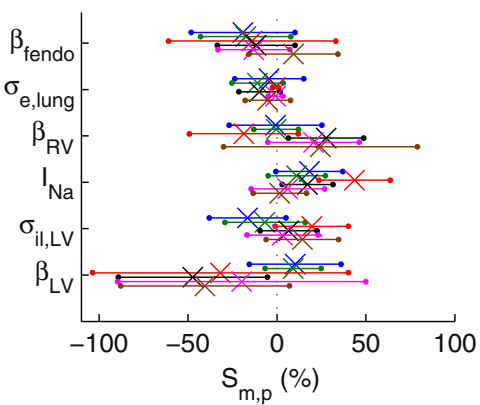

Fig. 6 Significant parameters following sensitivity analysis results for six ECG markers related with the QRS complex for the six patients (different colors for each patient): QRS peak time, QRS amplitude, QRS area, QRS-T interval, QRS skewness, and QRS kurtosis. Average values of the 12 ECG lead sensitivities represented by ' $x$ '. Limits of horizontal lines given by the average values \pm the standard deviation in the 12 leads 
as notable as those provoked by the parameters previously mentioned. Regarding the time interval between the QRS peak and the peak of the T-wave, the parameters exerting the strongest influence were those affecting cell repolarization in the six patients: $I_{\mathrm{CaL}}, \tau_{\mathrm{f}}, I_{\mathrm{Ks}}$ and $\tau_{\mathrm{xs}}$.

T-wave morphology As shown in Fig. 7, the temporal delay of the maximum peak of the T-wave, in absolute value, was mainly determined by ionic changes affecting cell repolarization, as occurred with the QRS-T interval: $I_{\mathrm{CaL}}, \tau_{\mathrm{f}}, I_{\mathrm{Ks}}$ and $\tau_{\mathrm{xs}}$. The main modulators of the amplitude of the Twave peak were the delayed rectifier potassium currents $\left(I_{\mathrm{Kr}}\right.$ and $\left.I_{\mathrm{Ks}}\right)$, as well as the sodium current $\left(I_{\mathrm{Na}}\right)$ and conduction properties in both $\mathrm{LV}\left(\beta_{\mathrm{LV}}, \sigma_{\mathrm{il}, \mathrm{LV}}, \sigma_{\mathrm{el}, \mathrm{LV}}\right.$ and $\left.\beta_{\text {fendo }}\right)$ and muscle in the torso $\left(\sigma_{\mathrm{e}, \text { musc }}\right)$. T-wave skewness was mainly determined by the values of $\beta_{\mathrm{LV}}, \beta_{\mathrm{RV}}, I_{\mathrm{Na}}, I_{\mathrm{Kr}}$, and $\tau_{\mathrm{f}}$. Similarly, T-wave kurtosis was modulated by $\beta_{\mathrm{LV}}, I_{\mathrm{Kr}}$, and $\tau_{\mathrm{f}}$. Interestingly, the biphasic behavior of the T-wave in some ECG leads in patient 6 led to large variations in both skewness and kurtosis in the sensitivity analysis (see Fig. 7). Only in this patient, another parameter played a role in the T-wave morphology $\left(\sigma_{\mathrm{ec}, \mathrm{LV}}\right)$.

\section{Discussion}

The sensitivity analysis performed in this study has shown that the tuning of very complex patient-specific models with a very high number of variables can be achieved by changing only a few parameters. Furthermore, the role of these key parameters was highly consistent between different patients. The goal of the analysis was to estimate the relative importance of parameters that cannot be observed clinically and, thus, the lack of counterintuitive results gives scientific evidence of what scientists would infer by intuition. As stated throughout the paper, about ten parameters were enough to tune both ECG morphology and LV activation maps. The low impact of the rest of the parameters was directly related to their smaller influence on myocardial electrical conduction or cellular action potential, as shown in previous studies [40]. The tuning procedure is performed manually, but the results presented in this study are an important step forward to create realistic human models in a more automated way in the future.

Sensitivity analyses for the study of human cardiac properties have been previously performed in silico in single cells or small tissues [7, 11, 20, 40, 42-46]. The influence of tissue extracellular conductivities on the ECG has been analyzed in a previous study using a human torso model fitted to a normal volunteer [19]. In this paper, we have gone a step further and performed a sensitivity analysis in models specifically tailored to six HF patients undergoing CRT implantation. We have reproduced the ECG measured at the body surface and the intracardiac electrical activation map with high accuracy, although some features like the morphology of the T wave in leads V5 and V6 for patients 1, 3 and 6 presented some differences with the measured ECG.

Previous studies have used patient-specific models for the study of cardiac properties in order to both provide
Fig. 7 Significant parameters following sensitivity analysis results for four ECG markers related with the T-wave for the six patients (different colors for each patient): T-wave peak time, $\mathrm{T}$-wave amplitude, T-wave skewness, and T-wave kurtosis. Average values of the 12 ECG lead sensitivities represented by ' $x$ '. Limits of horizontal lines given by the average values \pm the standard deviation in the 12 leads
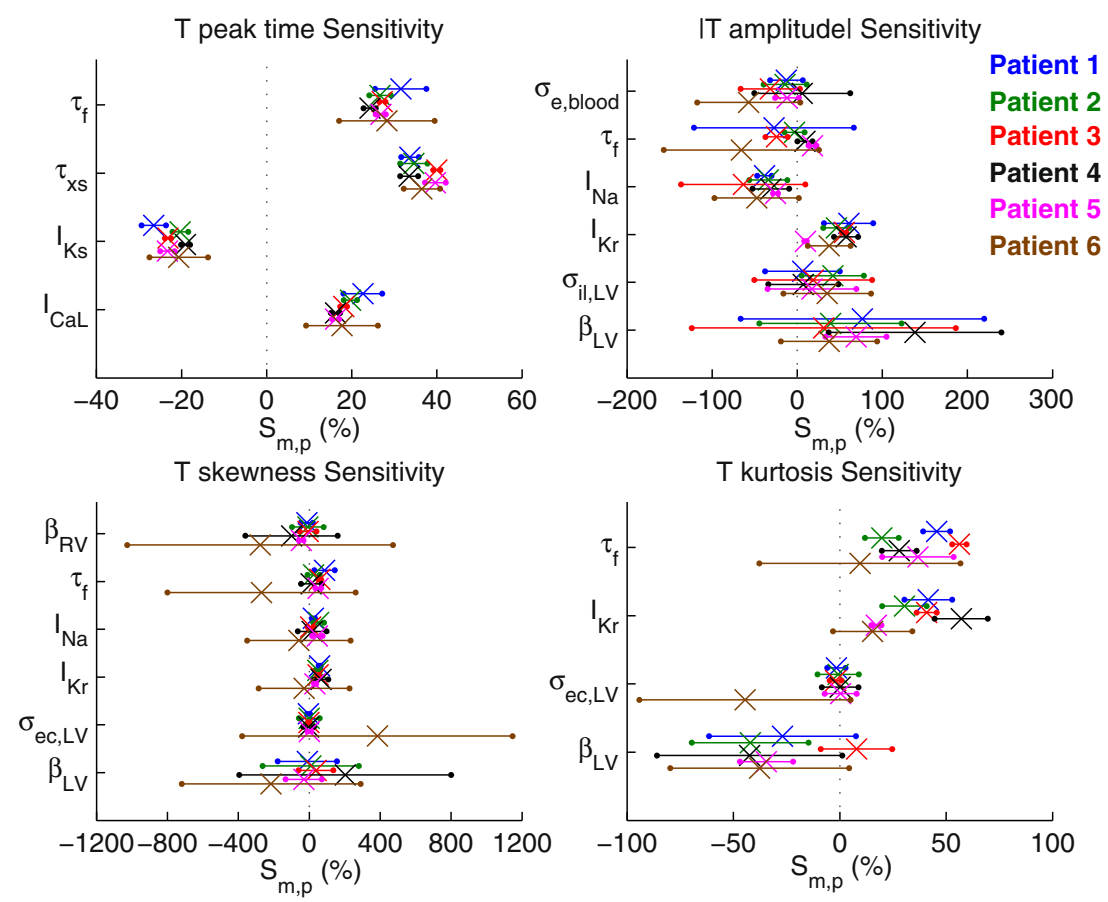

T kurtosis Sensitivity

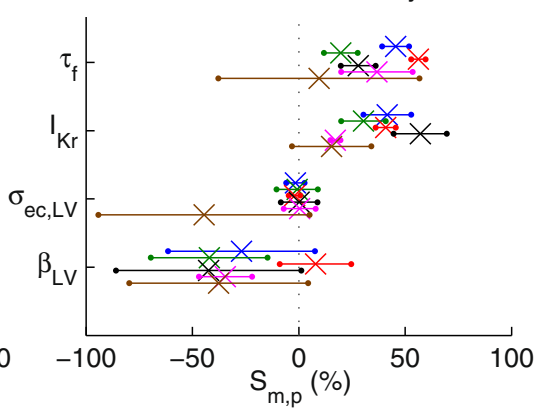


better predictions adapted to each patient and study underlying differences between them [1, 15, 23, 25, 29, 35]. The importance of conductivity parameters in the torso has also been a matter of study in recent works in both forward and inverse problems, focusing on different aspects like uncertainty in 3D visualization [8], anatomical segmentation [56], and realistic ECG simulation [4, 34, 51]. To the best of our knowledge, the work presented in this study is the first to be developed with complete models of the human torso, ventricular anatomy, and cellular electrophysiology adapted to specific patients.

A percentage of HF patients are diagnosed with LBBB. These patients present abnormally long QRS complexes with notching in some ECG leads [49]. These features required particular adjustments in the models, such as making the septum less conductive in our simulations. This finding is in agreement with clinical studies reporting an augmented transseptal time in these patients which does not necessarily involve slower propagation on the LV endocardium [2, 38, 50]. Notching was also favored by making LV cells more hypertrophic than those of the RV by decreasing $\beta_{\mathrm{LV}}$ as occurs in HF patients [16, 24, 32, 35, 57].

Two of the six patients included in this study presented scar in LV myocardium. These scarred areas were precisely located with CMR images and simulated in the models as non-excitable tissue, but the severity of tissue damage could not be assessed during the procedure in vivo. There could still be some conduction pathways that allow some electrical propagation, as observed in clinical data $[21,47]$. Nevertheless, the models of the two patients matched with notable accuracy both the ECG and the LV activation pattern, and the parameters modulating them were very consistent with those obtained in the other four patients.

\subsection{Limitations}

The model developed by Ten Tusscher and Panfilov in 2006 used for simulating ventricular cell electrophysiology has been used in numerous studies because it is one of the most complete human ventricular action potential models up to date $[26,33,36,37,55]$. Newer electrophysiological models of ventricular myocytes have been recently developed based on particular experimental datasets, but their robustness in reproducing tissue, cellular, and sub-cellular behavior has been shown to be similar $[10,17,30]$. Furthermore, previous studies have shown that HF entails remodeling of cellular electrophysiology in the myocardium [52] and included it in cellular models $[13,54]$. In this study, we used an undiseased human ventricular cell model as a reference, since we could not be sure about either to what extent ventricular cells had modified their electrophysiology for each patient or, considering they had modified it, whether their remodeling was homogeneous in both ventricles. Therefore, proper model tuning for each patient is an essential part of the model creation procedure. As a result of the choice of a different cell model, quantification of sensitivities could vary, but qualitative effects of particular parameter changes would probably remain similar. Moreover, the results of the sensitivity analysis performed in this study could not be directly extrapolated to patients with healthy hearts or other cardiac diseases.

Changes applied to the models in the sensitivity analysis were applied individually and in most cases homogeneously. Global sensitivity analysis with simultaneous changes in model parameters could provide more detailed information about possible synergistic effects, but the associated computational cost with such a large set of parameters would be extremely large [9, 53]. Furthermore, changes in parameters applied locally and/or heterogeneously could help in understanding properties of localized portions of tissue within the heart (low perfusion areas, scarred myocardium...). Our models contained various intrinsic heterogeneities in ionic parameters related to repolarization. Based mostly on data from animal hearts, this heterogeneity was implemented in subendocardial, midmyocardial, and subepicardial layers with differences between the LV and RV [55]. In addition, we used a $G_{\mathrm{Ks}}$ gradient related to the activation sequence. A recent study by Opthof et al. in 3 explanted normal human hearts has shown quite different patterns of heterogeneity [31]. It cannot be excluded that some results of our sensitivity analysis would have been different in the presence of these different baseline patterns.

The electroanatomical models specifically adapted to each patient were not guaranteed to be unique since other combinations of tuned parameters could possibly lead to matching of similar quality. However, in this study, we focused on quantifying the variations with respect to the default model, therefore the mechanisms involved in the modulation of the ECG and LV activation would not change. The number of patients used in the analysis was relatively small, but the high inter-patient consistency of the results suggests similar results would be obtained with an increased number of patients.

\section{Conclusion}

The sensitivity analysis shows that the effects of parameter variations on both ECG and LV activation are highly consistent between patients with specific anatomies and prognoses. Changes in ionic properties entail similar effects in all ECG leads, whereas the effects of changes in tissue conduction properties may vary between leads. Results of the analysis suggest that, in addition to the location of early activation sites, about 10 parameters suffice to create an 
accurate patient-specific model. Alterations in the remaining parameters are not significantly reflected in the ECG or in the ventricular electrical activation.

Acknowledgments This work was supported by a grant from the Swiss National Supercomputing Centre (CSCS) under project ID s598.

\section{References}

1. Aguado-Sierra J, Krishnamurthy A, Villongco C, Chuang J, Howard E, Gonzales MJ, Omens J, Krummen DE, Narayan S, Kerckhoffs RCP, McCulloch AD (2011) Patient-specific modeling of dyssynchronous heart failure: a case study. Prog Biophys Mol Biol 107(1):147-155

2. Auricchio A, Fantoni C, Regoli F, Carbucicchio C, Goette A, Geller C, Kloss M, Klein H (2004) Characterization of left ventricular activation in patients with heart failure and left bundle-branch block. Circulation 109(9):1133-1139

3. Bayés de Luna A, Batchvarov VN, Malik M (2006) The morphology of the electrocardiogram. In: Camm AJ, Luscher TF, Serruys PW (eds) The ESC textbook of cardiovascular medicine. Blackwell Publishers, Oxford

4. Boulakia M, Cazeau S, Fernández MA, Gerbeau JF, Zemzemi N (2010) Mathematical modeling of electrocardiograms: a numerical study. Ann Biomed Eng 38(3):1071-1097

5. Bradley CP, Pullan AJ, Hunter PJ (2000) Effects of material properties and geometry on electrocardiographic forward simulations. Ann Biomed Eng 28(7):721-741

6. Brignole M, Auricchio A, Baron-Esquivias G, Bordachar P, Boriani G, Breithardt OA, Cleland J, Deharo JC, Delgado V, Elliott PM, Gorenek B, Israel CW, Leclercq C, Linde C, Mont L, Padeletti L, Sutton R, Vardas PE, Zamorano JL, Achenbach S, Baumgartner H, Bax JJ, Bueno H, Dean V, Deaton C, Erol C, Fagard R, Ferrari R, Hasdai D, Hoes AW, Kirchhof P, Knuuti J, Kolh P, Lancellotti P, Linhart A, Nihoyannopoulos P, Piepoli MF, Ponikowski P, Sirnes PA, Tamargo JL, Tendera M, Torbicki A, Wijns W, Windecker S, Blomstrom-Lundqvist C, Badano LP, Aliyev F, Bänsch D, Bsata W, Buser P, Charron P, Daubert JC, Dobreanu D, Faerestrand S, Le Heuzey JY, Mavrakis H, McDonagh T, Merino JL, Nawar MM, Nielsen JC, Pieske B, Poposka L, Ruschitzka F, Van Gelder IC, Wilson CM (2013) 2013 ESC Guidelines on cardiac pacing and cardiac resynchronization therapy. Eur Heart J 34:2281-2329

7. Britton OJ, Bueno-Orovio A, Van Ammel K, Lu HR, Towart R, Gallacher DJ, Rodriguez B (2013) Experimentally calibrated population of models predicts and explains intersubject variability in cardiac cellular electrophysiology. Proc Natl Acad Sci U S A 110(23):E2098-2105

8. Burton BM, Erem B, Potter K, Rosen P, Johnson CR, Brooks DH, Macleod RS (2013) Uncertainty visualization in forward and inverse cardiac models. Comput Cardiol 40:57-60

9. Buzzard GT, Xiu D (2011) Variance-based global sensitivity analysis via sparse-grid interpolation and cubature. Commun Comput Phys 9(03):542-567

10. Carro J, Rodríguez JF, Laguna P, Pueyo E (2011) A human ventricular cell model for investigation of cardiac arrhythmias under hyperkalaemic conditions. Philos Trans R Soc A 369(1954):42054232

11. Chang ETY, Strong M, Clayton RH (2015) Bayesian sensitivity analysis of a cardiac cell model using a gaussian process emulator. PLoS ONE 10(6):e0130252
12. Conti CA, Votta E, Corsi C, De Marchi D, Tarroni G, Stevanella M, Lombardi M, Parodi O, Caiani EG, Redaelli A (2011) Left ventricular modelling: a quantitative functional assessment tool based on cardiac magnetic resonance imaging. Interface Focus 1(3):384395

13. Elshrif MM, Shi P, Cherry EM (2014) Electrophysiological properties under heart failure conditions in a human ventricular cell: a modeling study. In: Conference proceedings: annual international conference of the IEEE engineering in medicine and biology society 2014, pp 4324-4329

14. Fahy GJ, Pinski SL, Miller DP, McCabe N, Pye C, Walsh MJ, Robinson K (1996) Natural history of isolated bundle branch block. Am J Cardiol 77(14):1185-1190

15. Geerts L, Kerckhoffs R, Bovendeerd P, Arts T (2003) Towards patient specific models of cardiac mechanics: a sensitivity study. In: Proceedings of the 2nd international conference on functional imaging and modeling of the heart. Springer, Berlin, FIMH'03, pp $81-90$

16. Gradman AH, Alfayoumi F (2006) From left ventricular hypertrophy to congestive heart failure: management of hypertensive heart disease. Prog Cardiovasc Dis 48(5):326-341

17. Grandi E, Pandit SV, Voigt N, Workman AJ, Dobrev D, Jalife J, Bers DM (2011) Human atrial action potential and Ca2+ model: sinus rhythm and chronic atrial fibrillation. Circ Res 109(9):10551066

18. Kalayciyan R, Keller DUJ, Seemann G, Dössel O (2009) Creation of a realistic endocardial stimulation profile for the visible man dataset. In: Dössel O, Schlegel WC (eds) World congress on medical physics and biomedical engineering, 2009, Munich, Germany, no. 25/4 in IFMBE Proceedings. Springer, Berlin, pp 934-937

19. Keller D, Weber F, Seemann G, Dössel O (2010) Ranking the influence of tissue conductivities on forward-calculated ECGs. IEEE Trans Biomed Eng 57(7):1568-1576

20. Kharche S, Lüdtke N, Panzeri S, Zhang H (2009) A global sensitivity index for biophysically detailed cardiac cell models: a computational approach. In: Ayache N, Delingette H, Sermesant $M$ (eds) Functional imaging and modeling of the heart. Lecture Notes in Computer Science. Springer, Berlin, pp 366-375

21. Kohl P, Camelliti P, Burton FL, Smith GL (2005) Electrical coupling of fibroblasts and myocytes: relevance for cardiac propagation. J Electrocardiol 38(4, Supplement):45-50

22. Krause D, Potse M, Dickopf T, Krause R, Auricchio A, Prinzen F (2012) Poster: hybrid parallelization of a realistic heart model. In: Keller R, Kramer D, Weiss J-P (eds) Facing the multicore - challenge II; Aspects of new paradigms and technologies in parallel computing. Lecture Notes in Computer Science, vol 7174

23. Krueger MW, Rhode K, Weber FM, Keller DUJ, Caulfield D, Seemann G, Knowles BR, Razavi R, Dössel O (2010) Patient-specific volumetric atrial models with electrophysiological components: a comparison of simulations and measurements. In: Biomedizinische Technik/Biomedical Engineering, vol 55 (Suppl. 1)

24. Levy D, Larson MG, Vasan RS, Kannel WB, Ho KK (1996) The progression from hypertension to congestive heart failure. JAMA 275(20):1557-1562

25. MacLeod RS, Stinstra JG, Lew S, Whitaker RT, Swenson DJ, Cole MJ, Krüger J, Brooks DH, Johnson CR (2009) Subject-specific, multiscale simulation of electrophysiology: a software pipeline for image-based models and application examples. Phil Trans R Soc A 367(1896):2293-2310

26. Mincholé A, Pueyo E, Rodríguez JF, Zacur E, Doblaré M, Laguna P (2011) Quantification of restitution dispersion from the dynamic changes of the T-wave peak to end, measured at the surface ECG. IEEE Trans Biomed Eng 58(5):1172-1182

27. Myerburg RJ, Gelband H, Nilsson K, Castellanos A, Morales AR, Bassett AL (1978) The role of canine superficial ventricular muscle fibers in endocardial impulse distribution. Circ Res 42(1):27-35 
28. Neal ML, Kerckhoffs R (2010) Current progress in patientspecific modeling. Brief Bioinform 11(1):111-126

29. Nguyên UC, Potse M, Regoli F, Caputo ML, Conte G, Murzilli R, Muzzarelli S, Moccetti T, Caiani EG, Prinzen FW, Krause R, Auricchio A (2015) An in-silico analysis of the effect of heart position and orientation on the ECG morphology and vectorcardiogram parameters in patients with heart failure and intraventricular conduction defects. J Electrocardiol 48(4):617-625

30. O'Hara T, Virág L, Varró A, Rudy Y (2011) Simulation of the undiseased human cardiac ventricular action potential: model formulation and experimental validation. PLoS Comput Biol 7(5):e1002061

31. Opthof T, Remme CA, Jorge E, Noriega F, Wiegerinck RF, Tasiam A, Beekman L, Alvarez-Garcia J, Munoz-Guijosa C, Coronel R, Cinca J (2017) Cardiac activation-repolarization patterns and ion channel expression mapping in intact isolated normal human hearts. Heart Rhythm 14(2):265-272

32. Pitzalis MV, Iacoviello M, Romito R, Guida P, De Tommasi E, Luzzi G, Anaclerio M, Forleo C, Rizzon P (2005) Ventricular asynchrony predicts a better outcome in patients with chronic heart failure receiving cardiac resynchronization therapy. J Am Coll Cardiol 45(1):65-69

33. Potse M, Dubé B, Richer J, Vinet A, Gulrajani R (2006) A comparison of monodomain and bidomain reaction-diffusion models for action potential propagation in the human heart. IEEE Trans Biomed Eng 53(12):2425-2435

34. Potse M, Dubé B, Vinet A (2009) Cardiac anisotropy in boundaryelement models for the electrocardiogram. Med Biol Eng Comput 47(7):719-729

35. Potse M, Krause D, Kroon W, Murzilli R, Muzzarelli S, Regoli F, Caiani E, Prinzen FW, Krause R, Auricchio A (2014) Patientspecific modelling of cardiac electrophysiology in heart-failure patients. Europace 16(suppl 4):iv56-iv61

36. Pueyo E, Husti Z, Hornyik T, Baczkó I, Laguna P, Varró A, Rodríguez B (2010) Mechanisms of ventricular rate adaptation as a predictor of arrhythmic risk. Am J Physiol Heart Circ Physiol 298(5):H1577-1587

37. Pueyo E, Corrias A, Virág L, Jost N, Szél T, Varró A, Szentandrássy N, Nánási PP, Burrage K, Rodríguez B (2011) A multiscale investigation of repolarization variability and its role in cardiac arrhythmogenesis. Biophys J 101(12):2892-2902

38. Rodriguez LM, Timmermans C, Nabar A, Beatty G, Wellens HJ (2003) Variable patterns of septal activation in patients with left bundle branch block and heart failure. J Cardiovasc Electrophysiol 14(2):135-141

39. Roger VL, Go AS, Lloyd-Jones DM, Adams RJ, Berry JD, Brown TM, Carnethon MR, Dai S, de Simone G, Ford ES, Fox CS, Fullerton HJ, Gillespie C, Greenlund KJ, Hailpern SM, Heit JA, Ho PM, Howard VJ, Kissela BM, Kittner SJ, Lackland DT, Lichtman JH, Lisabeth LD, Makuc DM, Marcus GM, Marelli A, Matchar DB, McDermott MM, Meigs JB, Moy CS, Mozaffarian D, Mussolino ME, Nichol G, Paynter NP, Rosamond WD, Sorlie PD, Stafford RS, Turan TN, Turner MB, Wong ND, Wylie-Rosett J, American Heart Association Statistics Committee and Stroke Statistics Subcommittee (2011) Heart disease and stroke statistics-2011 update: a report from the American Heart Association. Circulation 123(4):e18-e209

40. Romero L, Pueyo E, Fink M, Rodríguez B (2009) Impact of ionic current variability on human ventricular cellular electrophysiology. Am J Physiol Heart Circ Physiol 297(4):H1436-1445

41. Sahli Costabal F, Hurtado DE, Kuhl E (2016) Generating Purkinje networks in the human heart. J Biomech 49(12):2455-2465

42. Sánchez C, Corrias A, Bueno-Orovio A, Davies M, Swinton J, Jacobson I, Laguna P, Pueyo E, Rodríguez B (2012) The $\mathrm{Na}+/ \mathrm{K}+$ pump is an important modulator of refractoriness and rotor dynamics in human atrial tissue. Am J Physiol Heart Circ Physiol 302(5):H1146-1159

43. Sánchez C, Bueno-Orovio A, Wettwer E, Loose S, Simon J, Ravens U, Pueyo E, Rodriguez B (2014) Inter-subject variability in human atrial action potential in sinus rhythm versus chronic atrial fibrillation. PLoS ONE 9(8):e105897

44. Sarkar AX, Sobie EA (2011) Quantification of repolarization reserve to understand interpatient variability in the response to proarrhythmic drugs: a computational analysis. Heart Rhythm 8(11):1749-1755

45. Sarkar AX, Christini DJ, Sobie EA (2012) Exploiting mathematical models to illuminate electrophysiological variability between individuals. J Physiol 590(Pt 11):2555-2567

46. Sobie EA, Sarkar AX (2011) Regression methods for parameter sensitivity analysis: applications to cardiac arrhythmia mechanisms. In: Annual international conference of the IEEE EMBS 2011, pp 4657-4660

47. Strauss DG, Selvester RH, Lima JAC, Arheden H, Miller JM, Gerstenblith G, Marbán E, Weiss RG, Tomaselli GF, Wagner GS, Wu KC (2008) ECG quantification of myocardial scar in cardiomyopathy patients with or without conduction defects correlation with cardiac magnetic resonance and arrhythmogenesis. Circ Arrhythm Electrophysiol 1(5):327-336

48. Strauss DG, Selvester RH, Wagner GS (2011) Defining left bundle branch block in the era of cardiac resynchronization therapy. Am J Cardiol 107(6):927-934

49. Surawicz B, Childers R, Deal BJ, Gettes LS, Bailey JJ, Gorgels A, Hancock EW, Josephson M, Kligfield P, Kors JA, Macfarlane P, Mason JW, Mirvis DM, Okin P, Pahlm O, Rautaharju PM, van Herpen G, Wagner GS, Wellens H, American Heart Association Electrocardiography and Arrhythmias Committee, Council on Clinical Cardiology, American College of Cardiology Foundation, Heart Rhythm Society (2009) AHA/ACCF/HRS recommendations for the standardization and interpretation of the electrocardiogram: part III: intraventricular conduction disturbances: a scientific statement from the American Heart Association Electrocardiography and Arrhythmias Committee, Council on Clinical Cardiology; the American College of Cardiology Foundation; and the Heart Rhythm Society. Endorsed by the International Society for Computerized Electrocardiology. J Am Coll Cardiol 53(11):976-981

50. Sweeney MO, Prinzen FW (2008) Ventricular pump function and pacing; physiological and clinical integration. Circ Arrhythm Electrophysiol 1(2):127-139

51. Swenson D, Levine J, Fu Z, Tate J, MacLeod R (2010) The effect of non-conformal finite element boundaries on electrical monodomain and Bidomain simulations. In: 2010 Computing in Cardiology, pp 97-100

52. Tomaselli GF, Marbán E (1999) Electrophysiological remodeling in hypertrophy and heart failure. Cardiovasc Res 42(2):270-283

53. Tondel K, Vik JO, Martens H, Indahl UG, Smith N, Omholt SW (2013) Hierarchical multivariate regression-based sensitivity analysis reveals complex parameter interaction patterns in dynamic models. Chemom Intell Lab 120:25-41

54. Trenor B, Cardona K, Gomez JF, Rajamani S, Ferrero JM, Belardinelli L, Saiz J (2012) Simulation and mechanistic investigation of the arrhythmogenic role of the late sodium current in human heart failure. PloS One 7(3):e32659

55. ten Tusscher KHWJ, Panfilov AV (2006) Alternans and spiral breakup in a human ventricular tissue model. Am J Physiol Heart Circ Physiol 291(3):H1088-1100

56. Wang L, Chitiboi T, Meine H, Günther M, Hahn HK (2016) Principles and methods for automatic and semi-automatic tissue segmentation in MRI data. Magn Reson Mater Phys 29(2):95-110

57. Zareba W, Klein H, Cygankiewicz I, Hall WJ, McNitt S, Brown M, Cannom D, Daubert JP, Eldar M, Gold MR, Goldberger JJ, 
Goldenberg I, Lichstein E, Pitschner H, Rashtian M, Solomon S, Viskin S, Wang P, Moss AJ, Investigators MADIT-CRT (2011) Effectiveness of cardiac resynchronization therapy by QRS morphology in the multicenter automatic defibrillator implantation trial-cardiac resynchronization therapy (MADIT-CRT). Circulation 123(10):1061-1072
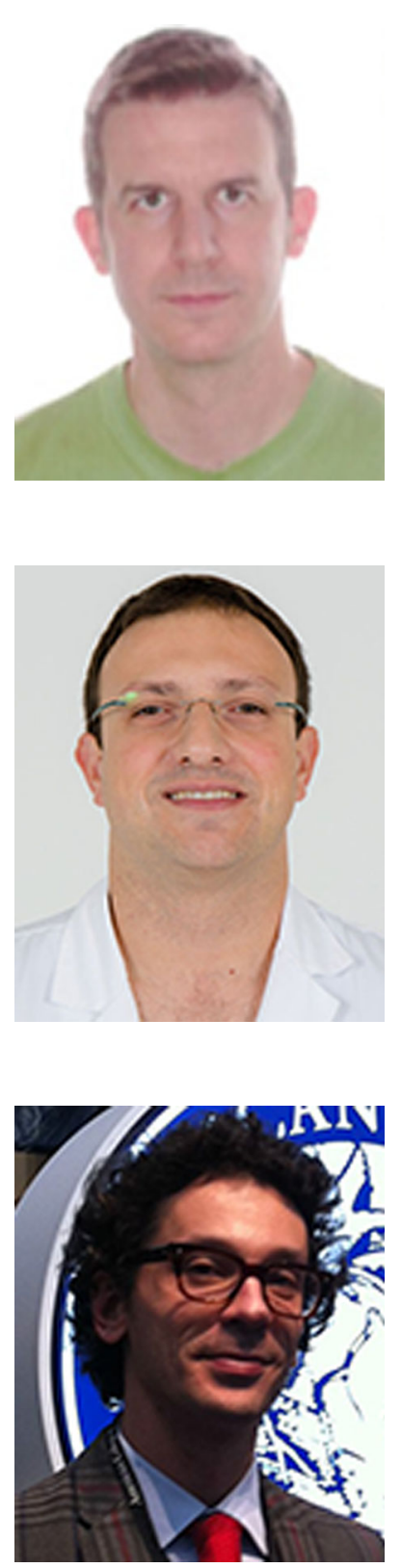

C. Sánchez is Assistant Professor at the Defense University Center (CUD), University of Zaragoza, Spain. His main field of interest is multiscale computational modelling of the human heart, and its applications.

G. D'Ambrosio is Cardiologist in training at Cardiocentro Ticino, Switzerland. He has an MSc degree in Information and Communication Technology in Cardiology and a Medical Degree from Sapienza University of Rome.

F. Maffessanti is Postdoctoral Research Associate at Università della Svizzera italiana, Switzerland. His primary research interests are cardiovascular mechanics and cardiac imaging.

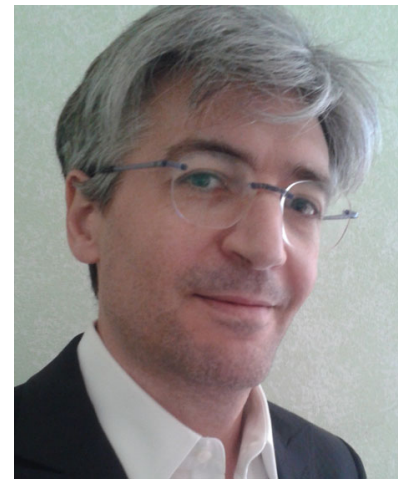

E. G. Caiani is Associate Professor at the Electronics, Information and Bioengineering Dpt., Politecnico di Milano, Italy. He got his MS in 1996 and $\mathrm{PhD}$ in Biomedical Engineering in 2000 .

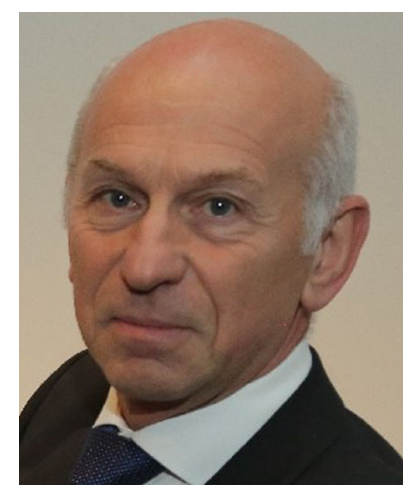

F. W. Prinzen is Professor of Physiology at Maastricht University, the Netherlands. His main research interest is the coupling of electrical activation and pump function of the heart in health and disease.

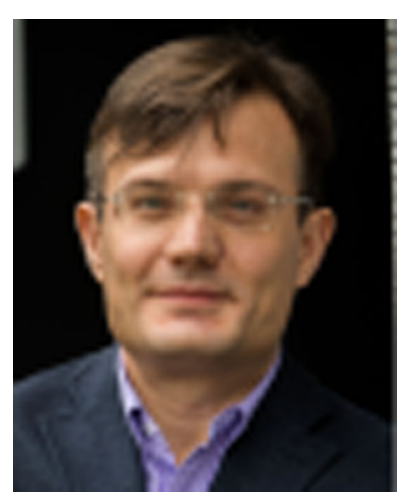

R. Krause is Director of the Institute of Computational Science, and Co-director of the Center for Computational Medicine in Cardiology at Università della Svizzera italiana, Switzerland.

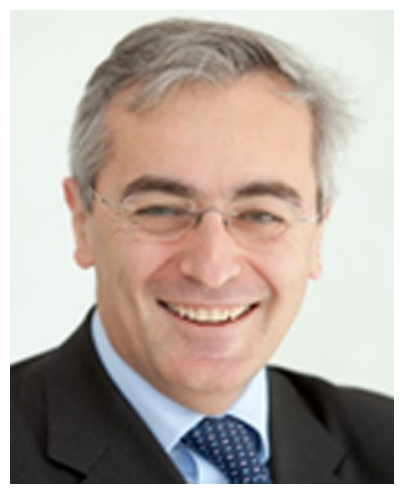

A. Auricchio is Director of the Clinical Electrophysiology Unit at Cardiocentro Ticino, and Co-director of the Center for Computational Medicine in Cardiology at Università della Svizzera italiana, Switzerland. 


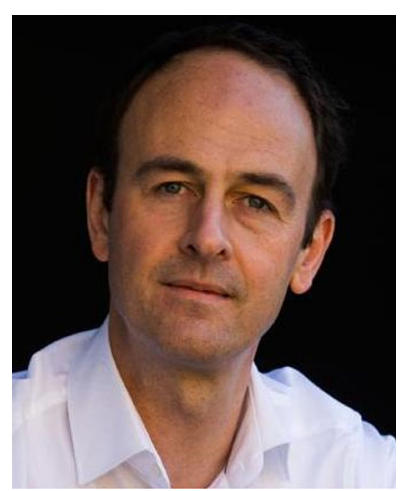

M. Potse is Research Scientist at Inria Bordeaux, France. $\mathrm{He}$ is interested in the application of numerical modeling and signal interpretation techniques to problems in cardiac electrophysiology. 